\title{
Impact of obesity on endometrial blood flow in women without polycystic ovarian syndrome during intracytoplasmic sperm injection
}

\author{
Xun Zeng ${ }^{1}$, Houqing Pang ${ }^{2}$, Xiaohong $\mathrm{Li}^{1}$, Shan Luo ${ }^{1}$, Song $\mathrm{Jin}^{1}$ and Shangwei $\mathrm{Li}^{1 *}$
}

\begin{abstract}
Background: Obesity may exert a negative effect on in vitro fertilization (IVF)/intracytoplasmic sperm injection (ICSI) treatment. However, the effect of obesity on the endometrium remains unknown. This study was designed to assess the effect of isolated body mass index (BMI) on endometrial blood supply in non-polycystic ovary syndrome (PCOS) women during ICSI by power Doppler Ultrasound.

Methods: An observational prospective study was carried out. A total of 206 patients without PCOS were divided into 4 groups based on Chinese BMl classification ( $\mathrm{kg} / \mathrm{m}(2)$ : underweight $(\mathrm{BMl}<18.5)$, normal weight (18.5 less than or equal to $\mathrm{BMI}<24$ ), overweight (24 less than or equal to $\mathrm{BMI}<28$ ), and obese (BMI greater than or equal to 28 ). Endometrial thickness, endometrial pattern, endometrial spiral arterial resistance index (RI) and pulsatility index (PI) values and systolic/diastolic ratio (S/D) were assessed on the day of human chorionic gonadotropin administration.

Results: Obese patients required more doses of gonadotrophin and longer stimulation duration than the normal weight patients $(P<0.05)$. Endometrial thickness and pattern were not statistically different between the $4 \mathrm{BMI}$ subgroups $(P>0.05)$. Subendometrial blood flow was detected in $165(80.1 \%)$ patients and spiral arterial PI was significantly higher in the obese group than in the normal weight and underweight groups $(P<0.05)$. All parameters of ICSI outcome were comparable, including pregnancy and miscarriage rates.

Conclusions: Obesity (BMl greater than or equal to $28 \mathrm{~kg} / \mathrm{m}(2))$ appears to exert a negative effect on endometrial and subendometrial blood flow based on the Chinese standard of obesity; however, it seems to have no significant effect on ICSI outcomes in non-PCOS women.
\end{abstract}

Keywords: Endometrial and subendometrial blood flow, Obesity, Power Doppler, Intracytoplasmic sperm injection

\section{Background}

Obesity is a chronic condition characterized by an accumulation of body fat. In recent years, the reproductive ability of the obese population has become a growing concern. The adverse effect of obesity on natural fecundity including subfertility (increased time to conception) $[1-3]$ and infertility $[4,5]$, has been reportedly attributed to oligoovulation or anovulation.

The impact of obesity on in vitro fertilization (IVF) outcome is controversial. Some studies reported that obese women experience longer ovarian stimulation and

\footnotetext{
*Correspondence: Iswivf100@sina.com

'Reproductive Medical Center, West China Second University Hospital,

Sichuan University, Chengdu, People's Republic of China

Full list of author information is available at the end of the article
}

require more gonadotropin ampoules [6] but respond poorly, with a decrease in the number of oocytes [6-8] and poorer outcomes, including impaired embryo quality, lower fertilization rate, and increased miscarriage rate $[9,10]$. However, no such effect has been noted in other studies $[11,12]$.

The effect of obesity on the endometrium has received less attention. The endometrium is the vascular mucosal lining of the uterus. Apart from endometrial thickness and pattern, an adequate endometrial blood supply is an essential requirement for implantation [13]. Advances in power Doppler ultrasonography allowed in vivo assessments of the endometrium, including morphologic (thickness and pattern) and functional (vascularization) parameters. Power Doppler is particularly useful for

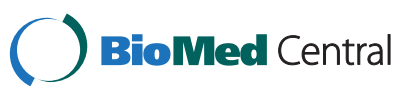


minute vessels with low-velocity flow and is less dependent on the angle between the beam and vessel; in areas of multiple vessels, the signal is additive, and opposite flow directions do not cancel each other's signals [14].

The sonographic endometrial region is defined as the area between both hyperechogenic margins of the endometrium, whereas the sonographic subendometrial region is considered a thin hypoechogenic layer at the myometrial-endometrial junction between the myometrium and endometrium on ultrasound [15]. Related studies found that the subendometrial region plays an important role in endometrial function [16]. Sufficient blood supply to the endometrium and subendometrium indicates good endometrial receptivity, and an absence of both is representative of an unfavorable uterine environment. Furthermore, lower spiral artery pulsatility index (PI) at the beginning of treatment or on the oocyte pick-up (OPU) day was found in pregnancy cycles compared to nonpregnancy cycles, whereas the spiral artery resistance index (RI) and systolic/diastolic ratio (S/D) did not differ between the groups along the course of treatment $[17,18]$.

A lack of evidence remains as to whether the body mass index (BMI) of infertile patients affects the endometrial blood flow during IVF. In Chinese women, the current World Health Organization's (WHO) definition of adult overweight (BMI $\left.>25 \mathrm{~kg} / \mathrm{m}^{2}\right)$ and obesity $\left(\mathrm{BMI}>30 \mathrm{~kg} / \mathrm{m}^{2}\right)$ may not be applicable. It had been suggested that BMI cut-off point for overweight or obesity for the Chinese population should be lower than that for the North American or European populations because obesity-associated metabolism is lower in Chinese individuals than in North American or European populations $[19,20]$. Therefore, we adopted the Chinese BMI cut-off values proposed by the Working Group on Obesity in China (WGOC) [21] and described in the Guidelines for Prevention and Control of Overweight and Obesity in Chinese Adults [22] to define overweight or obesity, as follows: $\mathrm{BMI}<18.5 \mathrm{~kg} / \mathrm{m}^{2}$ (underweight), $18.5 \leq \mathrm{BMI}<24 \mathrm{~kg} / \mathrm{m}^{2} \quad$ (normal weight), $24 \leq \mathrm{BMI}<$ $28 \mathrm{~kg} / \mathrm{m}^{2}$ (overweight), and BMI $\geq 28 \mathrm{~kg} / \mathrm{m}^{2}$ (obese). Because of the aforementioned concerns, we conducted this study in non-polycystic ovary syndrome (PCOS) women and assessed the effects of isolated BMI on the endometrial and subendometrial blood supply using the power Doppler technique during intracytoplasmic sperm injection (ICSI) cycles.

\section{Methods}

Two hundred and thirty-one consecutive women undergoing ICSI at the Reproductive Center of West China Second Hospital, Sichuan University between March 2011 and January 2012 were enrolled in our prospective cohort study. Each patient provided written informed consent before participating in the study, which was approved by the Ethics Committee of West China Second University Hospital of Sichuan University.

The inclusion criteria were as follows: age, <35 years, basal serum follicle stimulating hormone $(\mathrm{FSH}<10$ $\mathrm{mIU} / \mathrm{mL}$ ) level tested on day $2-3$ of a spontaneous cycle within 2-3 months before IVF treatment, regular menstrual cycle (26-33 days), and no PCOS. To exclude the effect of previous abortions and any possible interference from previous stimulation, only the first cycle for each patient without previous pregnancies was analyzed. The exclusion criteria were as follows: evidence of endometrial anomalies, anovulation, hypothalamic amenorrhea, and current or past diseases such as hepatic, renal, adrenal, or thyroid disorders that affected the ovaries or gonadotropin or sex steroid secretion or excretion.

Twenty-five women were excluded from the study. Six (2.6\%) had poor ovarian response, thus OPU was not performed. Fresh embryo transfer (ET) was cancelled in 14 women including $5(2.2 \%)$ with moderate to severe ovarian hyperstimulation, no embryo transferred was encountered in $4(1.7 \%)$ women, $3(1.3 \%)$ with a progesterone level of $>3 \mathrm{pg} / \mathrm{uL}$ on the day of human chorionic gonadotropin (hCG) administration, and 2 (0.9\%) with fluid accumulation in the uterine cavity observed on ultrasound on ET day. Five (2.2\%) women withdrew their informed consent. Finally, 206 consecutive patients were evaluated prospectively.

The height and weight of each patient was obtained to calculate the BMI immediately prior to treatment. Patients were categorized according to BMI as follows: underweight group (BMI $\left.<18.5 \mathrm{~kg} / \mathrm{m}^{2}\right)$, normal weight group $\left(18.5 \leq \mathrm{BMI}<24 \mathrm{~kg} / \mathrm{m}^{2}\right)$, overweight group ( $24 \leq$ $\left.\mathrm{BMI}<28 \mathrm{~kg} / \mathrm{m}^{2}\right)$, and obese group $\left(\mathrm{BMI} \geq 28 \mathrm{~kg} / \mathrm{m}^{2}\right)$.

All patients received a standard long protocol, starting with pituitary downregulation with a gonadotropinreleasing hormone agonist (GnRH-a, Decapeptyl, Ferring AG) during the mid-luteal phase. Then, ovarian stimulation was performed using recombinant follicle-stimulating hormone ( $\mathrm{rFSH}$, Gonal F, Serono), starting from days 2-3 of the next cycle. The initial daily FSH dose was adjusted for age, ovarian volume, and antral follicle count, and varied between 150 and 300 IU. Subsequent gonadotropin doses were adjusted based on the ovarian response as assessed by estradiol levels and follicular growth. 10,000 IU of urinary hCG was administered intramuscularly for ovulation induction when 2 or more follicles were $>18 \mathrm{~mm}$ in diameter. Oocyte retrieval was performed 35-37 h later by ultrasonographic-guided transvaginal puncture. Standard procedures were performed for gamete-embryo handling. Day 3 ET was performed in all cases. The embryos were graded on day 3 according to the following 3 characteristics: the form of the blastomeres, percentage of fragmentation, and cleavage rate. Luteal 
support was then given. Clinical pregnancy was defined as a sonographic visualization of intrauterine gestational sac 5 weeks after ET.

All patients underwent a transvaginal sonography (TVS) by a single ultrasound practice doctor who specialized in gynecological imaging. The ultrasound machine was an Acuson Sequoia 512 ultrasound system (Siemens, Mountain View, CA, USA). All ultrasound images were digitally stored and re-reviewed by a single reviewer (Author Song Jin) who specialized in gynecological sonography. Because of the reports of increased impedance of uterine arteries after hCG injection and its influence on the predictive value of ultrasonography [23], ultrasonography was performed on the day of hCG injection around 8-10 am after the patients had emptied their bladder. Endometrial thickness was measured from the echogenic interface of the junction of the myometrium and endometrium through the central longitudinal axis of the uterus. The endometrial pattern was classified as either a triple layer or non-triple layer. A triple layer endometrium presented a pattern in which the hyperechogenic outer lines and central hyperechogenic line were observed with a hypoechogenic region between them. A non-triple layer consisted of homogenous endometrial patterns characterized by either hyperechogenic or isoechogenic endometrium.

Using power Doppler with 6.0 MHz ultrasonography in the two-dimensional (2-D) mode in selected areas, endometrial blood flow was detected by endometrial or adjacent subendometrial regions within $10 \mathrm{~mm}$ of the echogenic endometrial borders. The endometrial-subendometrial blood flow distribution pattern was determined by the presence of pulsatile color signals in the subendometrial and endometrial regions. The endometrial-subendometrial blood flow distribution pattern [24] was classified as follows: Group A : No detectable endometrial or subendometrial flow; Group B: Presence of subendometrial flow only; and Group C: Presence of endometrial and subendometrial flow. If subendometrial flow was observed, Doppler studies were performed on the spiral artery with the highest color intensity within the innermost endometrial-subendometrial area in the upper part of the proximal uterine wall, obtained in the sagittal uterine plane. After confirming that the waveforms were continuous, an average of 3-5 cardiac cycles was selected for calculation of RI, PI, and S/D. Uterine circulation was assessed simultaneously in each examination; bilateral uterine arteries were sampled lateral to the cervix near the internal orifice. Mean values of bilateral uterine RI and PI were used for analysis.

\section{Statistical analysis}

Continuous variables were presented as the mean \pm standard deviation (SD) if normally distributed or given as the median (interquartile range) when not normally distributed. Analysis of variance (ANOVA) was applied to compare normally distributed data using the Bonferroni test for multiple post hoc analyses. Variables that were not normally distributed were analyzed using the KruskalWallis test and the Mann-Whitney $U$ test where appropriate. Chi-square and Fisher's exact tests were used to compare categorical data as appropriate. The Statistical Package for the Social Sciences 13.0 software (SPSS Inc., Chicago, IL, USA) was used for data analysis. $\mathrm{P}<0.05$ (two tailed) was considered statistically significant.

\section{Results}

Two hundred and six patients undergoing fresh autologous IVF/ICSI cycles were recruited: 42 in the underweight group, 80 in the normal weight group, 44 in the overweight group, and 40 in the obese group. All 4 BMI subgroups were comparable with regard to baseline characteristics including age, infertility duration, and day 3 FSH level (Table 1).

The overweight and obese groups required higher doses of gonadotropin and longer stimulation duration compared to the underweight and normal weight groups $(\mathrm{P}<0.05)$. The mean serum estradiol concentration on the day of hCG injection, mean number of oocytes obtained, and mean number of embryos transferred were comparable between the $4 \mathrm{BMI}$ subgroups $(\mathrm{P}>0.05)$.

The endometrial thickness, endometrial pattern, and uterine PI, RI, and S/D on the day of hCG injection were not statistically different between the 4 BMI groups $(P>0.05)$, although there was a trend toward decreased endometrial thickness as the BMI increased. For the distribution pattern of the endometrial-subendometrial blood flow on the day of hCG injection, the absence of endometrial and subendometrial flow (pattern A) was detected more frequently in the obese group than in the other 3 subgroups, although this difference did not reach statistical significance $(\mathrm{P}>0.05)$ (Table 2).

Subendometrial blood flow was detected in 165 (80.1\%) patients on the day of hCG injection. In these patients, spiral arterial PI was significantly higher in the obese group compared to the normal weight and underweight groups $(\mathrm{P}<0.05)$. However, the mean measurements of RI and S/D of the spiral arteries did not differ between the 4 groups $(\mathrm{P}>0.05)$ (Table 3$)$. No significant differences were observed in the pregnancy and miscarriage rates of the 4 BMI subgroups $(P>0.05)$ (Table 1$)$.

\section{Discussion}

To the best of our knowledge, this is the first study to use power Doppler ultrasound to evaluate the effect of BMI on endometrial and subendometrial blood flow in nonPCOS women during ICSI treatment using the Chinese standard of obesity. In the current study, a trend toward increased gonadotropin dose and stimulation duration 
Table 1 Baseline characteristics and ovarian response in non-PCOS women $(n=206)$ according to BMIs $\left(\mathrm{kg} / \mathrm{m}^{2}\right)$ in ICSI

\begin{tabular}{|c|c|c|c|c|c|}
\hline & $\mathrm{BMI}<18.5$ & $18.5 \leq \mathrm{BMI}<24$ & $24 \leq \mathrm{BMI}<28$ & $\mathrm{BMI} \geq \mathbf{2 8}$ & $\mathbf{P}$ \\
\hline No. of patients & 42 & 80 & 44 & 40 & - \\
\hline Age (y) & $28.9 \pm 4.5$ & $29.2 \pm 4.1$ & $29.0 \pm 3.9$ & $30.5 \pm 4.0$ & 0.830 \\
\hline Infertility duration (y) & $5.1 \pm 2.5$ & $4.9 \pm 2.7$ & $5.8 \pm 3.1$ & $5.5 \pm 3.0$ & 0.532 \\
\hline Day 3 FSH $(\mathrm{m} / \mathrm{U} / \mathrm{mL})$ & $5.8 \pm 2.2$ & $5.5 \pm 1.8$ & $5.9 \pm 2.0$ & $6.2 \pm 1.9$ & $0.426-$ \\
\hline Recombinant FSH dosage (IU) & $2013.5 \pm 771.6$ & $1996.4 \pm 884.2$ & $2433.2 \pm 997.4$ & $2952.7 \pm 1158.2$ & $<0.05^{c, d, e, f}$ \\
\hline Length of stimulation (days) & $8.2 \pm 2.7$ & $8.1 \pm 2.4$ & $9.9 \pm 2.2$ & $11.5 \pm 3.9$ & $<0.05^{\mathrm{c}, \mathrm{d}, \mathrm{e}, \mathrm{f}}$ \\
\hline Serum E2 $(p g / m l)^{b}$ & $2367.7 \pm 998.2$ & $2572.3 \pm 892.5$ & $2238.3 \pm 866.9$ & $2293.3 \pm 905.1$ & 0.340 \\
\hline Mean No. of oocytes obtained & $10.0 \pm 6.1$ & $9.8 \pm 5.7$ & $9.5 \pm 5.1$ & $8.9 \pm 5.9$ & 0.291 \\
\hline Mean No. of embryos transferred & $1.9 \pm 1.0$ & $2.0 \pm 1.0$ & $2.0 \pm 0.9$ & $1.9 \pm 0.9$ & 0.768 \\
\hline Mean grade of transferred embryos & $1.9 \pm 0.1$ & $2.0 \pm 0.2$ & $2.1 \pm 0.1$ & $2.0 \pm 0.1$ & 0.523 \\
\hline Pregnancy rate & 16/42 (38.1\%) & $36 / 80(45.0 \%)$ & 18/44 (40.9\%) & $14 / 40(35.0 \%)$ & 0.737 \\
\hline Miscarriage rate & $2 / 16(12.5 \%)$ & $4 / 36(11.1 \%)$ & $3 / 18(16.6 \%)$ & $2 / 14(14.2 \%)$ & 0.951 \\
\hline
\end{tabular}

Note: Values are mean $\pm \mathrm{SD}$.

${ }^{a}$ Number of patients (\%).

${ }^{\mathrm{b}}$ On the day of hCG.

c $P$ value obtained by group-to-group comparison, $B M l<18.5 \mathrm{~kg} / \mathrm{m}^{2}$ vs. $24 \leq \mathrm{BMl}<28 \mathrm{~kg} / \mathrm{m}^{2}$.

${ }^{d} P$ value obtained by group-to-group comparison, $B M I<18.5 \mathrm{~kg} / \mathrm{m}^{2} \mathrm{vs} . \geq 28 \mathrm{~kg} / \mathrm{m}^{2}$.

e $P$ value obtained by group-to-group comparison, $18.5 \leq \mathrm{BMl}<24 \mathrm{~kg} / \mathrm{m}^{2} \mathrm{vs}$. $24 \leq \mathrm{BMl}<28 \mathrm{~kg} / \mathrm{m}^{2}$.

${ }^{f} \mathrm{P}$ value obtained by group-to-group comparison, $18.5 \leq \mathrm{BMl}<24 \mathrm{~kg} / \mathrm{m}^{2} \mathrm{vs}$. $\geq 28 \mathrm{~kg} / \mathrm{m}^{2}$.

was noted in obese women compared to normal weight women. In the patient whose subendometrial blood flow was detected, the RI and S/D measurements were comparable between the 4 BMI subgroups, although spiral arterial PI was significantly higher in the obese group than in the normal weight group. However, this did not translate to inferior pregnancy outcomes, as the clinical pregnancy and miscarriage rates were comparable between the 4 BMI groups.

Increasing evidence on the effect of obesity on IVF treatment has shown that increased BMI has adverse effects on ovarian stimulation response [8,10,25-27]. Li et al. [25] reported that overweight women (BMI $\geq$ $24 \mathrm{~kg} / \mathrm{m}^{2}$ ) required more ampoules of gonadotropin, had

Table 2 Endometrial thickness, pattern and endometrial-subendometrial flow distribution pattern in women without PCOS $(\mathbf{n}=206)$ according to BMls $\left(\mathrm{kg} / \mathrm{m}^{2}\right)$

\begin{tabular}{|c|c|c|c|c|c|}
\hline & $\begin{array}{c}\text { BMI }<18.5 \\
(n=42)\end{array}$ & $\begin{array}{c}18.5 \leq B M I<24 \\
(n=80)\end{array}$ & $\begin{array}{c}24 \leq B M I<28 \\
(n=44)\end{array}$ & $\begin{array}{c}\mathrm{BMI} \geq 28 \\
(\mathrm{n}=40)\end{array}$ & $\mathbf{P}$ \\
\hline Endometrial thickness ( $\mathrm{mm}$ ) & $10.6 \pm 2.1$ & $10.5 \pm 2.3$ & $10.1 \pm 2.2$ & $9.5 \pm 2.9$ & 0.055 \\
\hline Endometrial pattern $^{a}$ & & & & & 0.872 \\
\hline Triple layer & $34(81.0)$ & $65(81.3)$ & $35(79.5)$ & $30(75.0)$ & \\
\hline Non-triple layer & $8(19.0)$ & $15(18.7)$ & $9(20.5)$ & $10(25.0)$ & \\
\hline Endometrial blood flow distribution pattern ${ }^{a}$ & & & & & 0.149 \\
\hline A :subendometrial flow (-), endometrial flow (-) & $9(21.4)$ & $11(13.8)$ & $10(22.7)$ & $11(27.5)$ & \\
\hline$B$ :subendometrial flow (+), endometrial flow (-) & $13(31.0)$ & $22(27.5)$ & $13(29.5)$ & $17(42.5)$ & \\
\hline C :subendometrial flow (+), endometrial flow (+) & $20(47.6)$ & $47(58.7)$ & $21(47.7)$ & $12(30.0)$ & \\
\hline \multirow[t]{2}{*}{ Uterine $P I^{b}$} & 2.10 & 2.11 & 2.11 & 2.13 & 0.413 \\
\hline & $(1.49-2.76)$ & $(1.41-2.86)$ & $(1.38-2.87)$ & $(1.33-3.08)$ & \\
\hline \multirow[t]{2}{*}{ Uterine $R^{b}$} & 0.80 & 0.81 & 0.82 & 0.82 & 0.683 \\
\hline & $(0.63-0.87)$ & $(0.72-0.89)$ & $(0.71-0.87)$ & $(0.73-0.92)$ & \\
\hline \multirow[t]{2}{*}{ Uterine $S / D^{b}$} & 5.69 & 5.71 & 5.70 & 5.89 & 0.561 \\
\hline & $(4.33-6.89)$ & $(4.50-6.92)$ & $(4.61-7.03)$ & $(4.23-6.95)$ & \\
\hline
\end{tabular}

Note: Values are mean \pm SD.

$R /$ resistance index, $P /$ pulsatility Index, $S / D$ the ratio between peak systolic flow and lowest diastolic flow.

${ }^{\text {a }}$ Number of patients (\%).

${ }^{\mathrm{b}}$ Values given as median (range). 
Table 3 Spiral flow parameters in women without PCOS whose subendometrial flow can be detected $(n=165)$ according to BMls $\left(\mathbf{k g} / \mathrm{m}^{2}\right)$

\begin{tabular}{lccccc}
\hline & $\begin{array}{c}\mathbf{B M I}<\mathbf{1 8 . 5} \\
(\mathbf{n}=\mathbf{3 3})\end{array}$ & $\begin{array}{c}\mathbf{1 8 . 5} \leq \mathbf{B M I}<\mathbf{2 4} \\
(\mathbf{n}=\mathbf{6 9})\end{array}$ & $\begin{array}{c}\mathbf{2 4} \leq \mathbf{B M I}<\mathbf{2 8} \\
(\mathbf{n}=\mathbf{3 4})\end{array}$ & $\begin{array}{c}\mathbf{B M I} \geq \mathbf{2 8} \\
(\mathbf{n}=\mathbf{2 9})\end{array}$ \\
\hline Spiral PI & $1.00(0.80-1.39)$ & $0.96(0.75-1.45)$ & $1.14(0.78-1.55)$ & $1.29(0.77-1.62)$ & $\mathbf{P}$ \\
Spiral RI & $0.59(0.52-0.64)$ & $0.60(0.52-0.67)$ & $0.61(0.56-0.62)$ & $0.61(0.56-0.70)$ & $0.05^{\mathrm{a}, \mathrm{b}}$ \\
Spiral S/D & $2.91(2.72-3.21)$ & $2.90(2.60-3.24)$ & $2.95(2.70-3.41)$ & $3.02(2.71-3.35)$ & 0.382 \\
\hline
\end{tabular}

Note: Values are median (range). $R I$ resistance index, $P I$ pulsatility Index, $S / D$ the ratio between peak systolic flow and lowest diastolic flow.

a $P$ value obtained by group-to-group comparison, $B M l<18.5 \mathrm{~kg} / \mathrm{m}^{2} \mathrm{vs} . \geq 28 \mathrm{~kg} / \mathrm{m}^{2}$.

${ }^{b} \mathrm{P}$ value obtained by group-to-group comparison, $18.5 \leq \mathrm{BMl}<24 \mathrm{~kg} / \mathrm{m}^{2} \mathrm{vs}$. $\geq 28 \mathrm{~kg} / \mathrm{m}^{2}$.

lower peak E2 concentration along with increased cycle cancellation because of insufficient follicle development. Orvieto et al. [26] and Dokras et al. [27] reported similar results in obese women $\left(\mathrm{BMI}>30 \mathrm{~kg} / \mathrm{m}^{2}\right)$. In the present study, we demonstrated that obesity increased the required gonadotropin dose and stimulation duration. The reason for gonadotropin resistance in obesity is unclear; however, alterations in serum and follicular concentrations of adipokine leptin might be involved [28]. Higher leptin levels can directly attenuate insulin, insulin-like growth factor-1, and transforming growth factor- $\beta$ [29], which may adversely affect granulosa cell function [30] and thecal cell steroidogenesis, and simultaneously suppresses follicular growth by reducing sensitivity to gonadotropin stimulation [31]. The doses were not similarly initiated and maintained in the 4. BMI groups. Therefore, in women with lower ovarian response, gonadotropin doses and stimulation duration were increased; these women were frequently obese. Thus, despite the state of gonadotropin resistance in the obese group, similar serum estradiol concentrations on the day of hCG injection and comparable numbers of retrieved oocytes were achieved in 4 BMI subgroups.

Uterine receptivity is more important than is currently believed. Because of insufficient knowledge on the role of the endometrium in the reproductive performance of obese patients, our study focused primarily on the endometrial factor. Previous studies focusing on the effects of BMI on the endometrium only evaluated the association between endometrial thickness and BMI, demonstrating conflicting results. $\mathrm{Ku}$ et al. reported no significant difference in endometrial thickness on the day of hCG injection between women with $\mathrm{BMI}<24 \mathrm{~kg} / \mathrm{m}^{2}$ and those with $\mathrm{BMI} \geq 24 \mathrm{~kg} / \mathrm{m}^{2}$; however, the clinical pregnancy rate was lower in the latter [32]. Esinler et al. also reported comparable endometrial thickness in different BMI subgroups [33]. However, Nichols et al. noted that the mean endometrial thickness on the day of retrieval was increased in obese women $\left(\mathrm{BMI} \geq 28 \mathrm{~kg} / \mathrm{m}^{2}\right)$, with a significant reduction in pregnancy rate compared to underweight $\left(\mathrm{BMI}<20 \mathrm{~kg} / \mathrm{m}^{2}\right)$ or normal-weight women (BMI $20-27.9 \mathrm{~kg} / \mathrm{m}^{2}$ ) [34]. In our study, the endometrial thickness and pattern on the day of hCG administration was not significantly different between the 4 BMI subgroups; however, a nonsignificant trend toward increased endometrial thickness was noted with higher BMI. Differences in the BMI cutoff values and inclusion criteria may be one of the reasons for these conflicting results. In our study, we use the Chinese BMI cut-off values and only the first cycle for each patient without previous pregnancies was analyzed; therefore, the influence of previous abortions and any possible interference from previous stimulation on the endometrial growth was avoided. However, the 3 aforementioned studies did not consider this factor.

A high degree of endometrial perfusion is an essential requirement for early endometrial response to blastocyst implantation, and vascular changes may affect uterine receptivity [35]. The significant increase in endometrial microvascular blood flow periovulation affects endometrial growth, blood supply, and implantation [13]. The presence of both endometrial and subendometrial blood flow on color or power Doppler examination has been used as an indicator of sufficient endometrial receptivity, whereas the absence of both represents a poor uterine environment. Zaidi et al. [36] assessed the power Doppler image of the endometrial strip on the day of hCG administration and showed that patients who did not develop both endometrial and subendometrial vascularization were associated with implantation failure. Similar conclusions were obtained by Chein et al. [24]. They reported that subendometrial blood flow was detected in 477 (76.6\%) patients; pregnancy and implantation rates were significantly higher in these patients than in those with no detectable flow $(\mathrm{P}<0.0001)$.

Increased impedance in the subendometrial arteries could be expected in cases of diminished endometrial vascularization and perfusion. Higher spiral arterial PI appears to negatively affect endometrial blood vessel function. Gorokhovsky et al. [17] assessed 39 women undergoing IVF and found significantly reduced spiral artery PI values in pregnancy cycles compared to nonpregnancy cycles at the beginning of treatment. Spiral artery RI and S/D did not differ between these groups along the treatment course. Similar conclusions for endometrial Doppler assessment of spiral artery RI 
and S/D were reached by Battaglia et al. and they demonstrated a significantly lower PI in spiral arteries on the day of OPU in pregnancy cycles compared with nonpregnancy cycles[18]. However, another study found no difference in the measurements of PI, RI, and S/D between pregnant and nonpregnant patients [14].

No data are available concerning the effects of BMI on endometrial perfusion in women during IVF cycles. In the present study, we measured resistance to flow in the endometrium using the Power Doppler technique and noted more frequent absence of endometrial and subendometrial flow on the day of hCG injection in the obese group than in the other 3 subgroups, although this difference did not reach statistical significance. Subendometrial blood flow was detected in $165(80.1 \%)$ patients on the day of hCG injection. In these patients, the spiral arterial PI was significantly higher in the obese group than in the normal weight group, but the RI and S/D measurements were comparable in the 4 BMI subgroups. The significant difference in PI, but not in RI and S/D, could be related to the PI calculation method, which takes the entire spectral Doppler waveform into account and not just the maximal and minimal frequency shifts, as in the calculation of RI and S/D [17]. Sivitz et al. [37] reported that microvascular vasodilator function is impaired in obese women, and women appeared more sensitive to the deleterious effect of obesity on endothelium-mediated resistance vessel function. Obesity appears to negatively affect endometrial blood supply because of the higher PI value in obese women than in the controls.

Despite the lack of knowledge on the role of the endometrium in the reproductive performance of obese patients, most reports show lower implantation and pregnancy rates and higher miscarriage rates $[5,9,10]$. However, other authors have not found a detrimental effect of increased BMI on IVF/ICSI outcomes [12,33]. Dechaud et al. [12] examined 573 patients who underwent 789 IVF cycles and found that all parameters of IVF outcome were comparable between different BMI subgroups, including the cancellation, implantation, and pregnancy rates, with the exception of significantly increased required r-FSH dose in the obese group. A retrospective study of 775 patients who underwent 1113 ICSI cycles showed that endometrial thickness was comparable in different BMI subgroups, and isolated high BMI $\left(\geq 30 \mathrm{~kg} / \mathrm{m}^{2}\right)$ only negatively affected ovarian stimulation response and availability of cryopreservable embryos [33]. In our study, the pregnancy and miscarriage rates did not differ between the 4 BMI subgroups. This finding could be explained mainly by the lack of differences in the number of embryos transferred and the mean grade of transferred embryos in our study, as the poor embryo quality described in obese women has been the main parameter related to increased risk of implantation failure and miscarriage [38,39].

Several caveats should be considered when comparing the results of the effect of obesity on IVF outcome. The lack of consensus regarding the impact of obesity on ovarian response, endometrial thickness and pattern, clinical pregnancy rate, and miscarriage rate might be partly explained by the different definitions of normal weight, overweight, or obesity as defined by the BMI values used to create study groups. The distribution of BMI differs according to ethnicity and environment. It has been demonstrated that Chinese individuals have similar distributions of glucose and lipid factors at significantly lower BMI values compared with European individuals [19]. The WHO criteria derived in European populations may not apply to Chinese populations. We adopted different BMI cutoff limits largely derived from Chinese population studies demonstrating that a BMI of $18.5-23.9 \mathrm{~kg} / \mathrm{m}^{2}$ should be considered "normal," a BMI between 24.0 and $27.9 \mathrm{~kg} / \mathrm{m}^{2}$ considered "overweight," and a BMI of $\geq 28.0 \mathrm{~kg} / \mathrm{m}^{2}$ considered "obese" [22]. Therefore, the validity of the current results is dependent on the Chinese classification of BMI used in our study.

Our study was a prospective, observational trial with a homogenous sample in which the ovarian stimulation protocol and some confounding factors such as age, the first ICSI cycle, and PCOS were taken into consideration. There is a current worldwide epidemic of both obesity and PCOS, and PCOS is frequently associated with increased BMI. Furthermore, PCOS is also the most common cause of anovulatory infertility and is associated with many adverse ART outcomes. However, the majority of studies with conflicting results in this context do not discriminate between isolated obesity and PCOS. Therefore, it is essential to exclude such patients in order to delineate the effect of isolated obesity on ICSI outcome, as in the present study.

\section{Conclusions}

According to the Chinese classification of BMI, obese women required more doses of gonadotrophin and longer stimulation duration than normal weight women. Isolated obesity had a negative impact on endometrial and subendometrial blood flow. However, this did not translate to inferior pregnancy outcomes, since the clinical pregnancy and miscarriage rates were comparable between all BMI subgroups. Further studies should explore other morphologic, sonographic, and endocrine parameters to determine the associations between obesity, the endometrium, and IVF outcomes. 


\section{Competing interests}

The authors declare that they have no competing interests.

\section{Authors' contributions}

$X Z$ conceived and drafted the manuscript. HQP designed the study and performed ultrasound examination. XHL designed the study and performed statistical analysis of data. SL participated in the data collection and drafted the manuscript. SJ participated in the ultrasound image collection and interpreted the data. ZW supervised the team and the study. All authors read and approved the final manuscript.

\section{Acknowledgements}

We sincerely thank our colleague Jiao Chen for the excellent technical assistance. This article was revised by a professional English language service of Editage.

\section{Author details}

${ }^{1}$ Reproductive Medical Center, West China Second University Hospital, Sichuan University, Chengdu, People's Republic of China. 'Ultrasound department, West China Second University Hospital, Sichuan University, Chengdu, People's Republic of China.

Received: 4 April 2013 Accepted: 24 June 2013

Published: 26 June 2013

\section{References}

1. Wise LA, Rothman KJ, Mikkelsen EM, Sorensen HT, Riis A, Hatch EE: An internet-based prospective study of body size and time-to-pregnancy. Hum Reprod 2010, 25(1):253-264

2. Bolumar F, Olsen J, Rebagliato M, Saez-Lloret I, Bisanti L: Body mass index and delayed conception: a European Multicenter Study on Infertility and Subfecundity. Am J Epidemiol 2000, 151(11):1072-1079.

3. Jensen TK, Scheike T, Keiding N, Schaumburg I, Grandjean P: Fecundability in relation to body mass and menstrual cycle patterns. Epidemiology 1999, 10(4):422-428.

4. van der Steeg JW, Steures P, Eijkemans MJ, Habbema JD, Hompes PG, Burggraaff JM, Oosterhuis GJ, Bossuyt PM, van der Veen F, Mol BW: Obesity affects spontaneous pregnancy chances in subfertile, ovulatory women. Hum Reprod 2008, 23(2):324-328.

5. Awartani KA, Nahas S, Al Hassan SH, Al Deery MA, Coskun S: Infertility treatment outcome in sub groups of obese population. Reprod Biol Endocrinol 2009, 7:52.

6. Fedorcsak P, Dale PO, Storeng R, Ertzeid G, Bjercke S, Oldereid N, Omland AK, Abyholm T, Tanbo T: Impact of overweight and underweight on assisted reproduction treatment. Hum Reprod 2004, 19(11):2523-2528.

7. Wittemer C, Ohl J, Bailly M, Bettahar-Lebugle K, Nisand I: Does body mass index of infertile women have an impact on IVF procedure and outcome? J Assist Reprod Genet 2000, 17(10):547-552.

8. Matalliotakis I, Cakmak H, Sakkas D, Mahutte N, Koumantakis G, Arici A: Impact of body mass index on IVF and ICSI outcome: a retrospective study. Reprod Biomed Online 2008, 16(6):778-783.

9. Rittenberg V, Seshadri S, Sunkara SK, Sobaleva S, Oteng-Ntim E, El-Toukhy T: Effect of body mass index on IVF treatment outcome: an updated systematic review and meta-analysis. Reprod Biomed Online 2011, 23(4):421-439.

10. Zhang D, Zhu Y, Gao H, Zhou B, Zhang R, Wang T, Ding G, Qu F, Huang H, Lu X: Overweight and obesity negatively affect the outcomes of ovarian stimulation and in vitro fertilisation: a cohort study of 2628 Chinese women. Gynecol Endocrinol 2010, 26(5):325-332.

11. Martinuzzi K, Ryan S, Luna M, Copperman AB: Elevated body mass index (BMI) does not adversely affect in vitro fertilization outcome in young women. J Assist Reprod Genet 2008, 25(5):169-175.

12. Dechaud H, Anahory T, Reyftmann L, Loup V, Hamamah S, Hedon B: Obesity does not adversely affect results in patients who are undergoing in vitro fertilization and embryo transfer. Eur J Obstet Gynecol Reprod Biol 2006, 127(1):88-93.

13. Jinno $M$, Ozaki T, Iwashita M, Nakamura $Y$, Kudo A, Hirano H: Measurement of endometrial tissue blood flow: a novel way to assess uterine receptivity for implantation. Fertil Steril 2001, 76(6):1168-1174.
14. Yuval Y, Lipitz S, Dor J, Achiron R: The relationships between endometrial thickness, and blood flow and pregnancy rates in in-vitro fertilization. Hum Reprod 1999, 14(4):1067-1071.

15. Xavier P, Beires J, Barros H, Martinez-de-Oliveira J: Subendometrial and intraendometrial blood flow during the menstrual cycle in patients with endometriosis. Fertil Steril 2005, 84(1):52-59.

16. Lesny P, Killick SR, Tetlow RL, Manton DJ, Robinson J, Maguiness SD: Ultrasound evaluation of the uterine zonal anatomy during in-vitro fertilization and embryo transfer. Hum Reprod 1999, 14(6):1593-1598.

17. Gorokhovsky R, Tal J, Leibovitz Z, Degani S, Shapiro I, Calderon I, Paltiely Y, Ohel G: Subendometrial arterial spectral doppler assessment during IVF cycles and its correlation with treatment outcome. Ultrasound Med Biol 2006, 32(2):157-162.

18. Battaglia C, Artini PG, Giulini S, Salvatori M, Maxia N, Petraglia F, Volpe A: Colour Doppler changes and thromboxane production after ovarian stimulation with gonadotrophin-releasing hormone agonist. Hum Reprod 1997, 12(11):2477-2482.

19. Razak F, Anand SS, Shannon H, Vuksan V, Davis B, Jacobs R, Teo KK, McQueen M, Yusuf S: Defining obesity cut points in a multiethnic population. Circulation 2007, 115(16):2111-2118.

20. Jia WP, Xiang KS, Chen L, Lu JX, Bao YQ, Wu YM, Jiang SY: A comparison of the application of two working definitions of metabolic syndrome in Chinese population. Zhonghua Yi Xue Za Zhi 2004, 84(7):534-538.

21. Zhou BF: Effect of body mass index on all-cause mortality and incidence of cardiovascular diseases-report for meta-analysis of prospective studies open optimal cut-off points of body mass index in Chinese adults. Biomed Environ Sci 2002, 15(3):245-252.

22. Chen C, Lu FC: The guidelines for prevention and control of overweight and obesity in Chinese adults. Biomed Environ Sci 2004, 17(Suppl):1-36.

23. Bassil S, Magritte JP, Roth J, Nisolle M, Donnez J, Gordts S: Uterine vascularity during stimulation and its correlation with implantation in in-vitro fertilization. Hum Reprod 1995, 10(6):1497-1501.

24. Chien LW, Au HK, Chen PL, Xiao J, Tzeng CR: Assessment of uterine receptivity by the endometrial-subendometrial blood flow distribution pattern in women undergoing in vitro fertilization-embryo transfer. Fertil Steril 2002, 78(2):245-251.

25. Li Y, Yang D, Zhang Q: Impact of overweight and underweight on IVF treatment in Chinese women. Gynecol Endocrinol 2010, 26(6):416-422.

26. Orvieto R, Meltcer S, Nahum R, Rabinson J, Anteby EY, Ashkenazi J: The influence of body mass index on in vitro fertilization outcome. Int J Gynaecol Obstet 2009, 104(1):53-55.

27. Dokras A, Baredziak L, Blaine J, Syrop C, VanVoorhis BJ, Sparks A: Obstetric outcomes after in vitro fertilization in obese and morbidly obese women. Obstet Gynecol 2006, 108(1):61-69.

28. Butzow TL, Moilanen JM, Lehtovirta M, Tuomi T, Hovatta O, Siegberg R, Nilsson CG, Apter D: Serum and follicular fluid leptin during in vitro fertilization: relationship among leptin increase, body fat mass, and reduced ovarian response. J Clin Endocrinol Metab 1999, 84(9):3135-3139.

29. Agarwal SK, Vogel K, Weitsman SR, Magoffin DA: Leptin antagonizes the insulinlike growth factor-I augmentation of steroidogenesis in granulosa and theca cells of the human ovary. J Clin Endocrinol Metab 1999, 84(3):1072-1076.

30. Ghizzoni L, Barreca A, Mastorakos G, Furlini M, Vottero A, Ferrari B, Chrousos GP, Bernasconi S: Leptin inhibits steroid biosynthesis by human granulosa-lutein cells. Horm Metab Res 2001, 33(6):323-328.

31. Srivastava RK, Krishna A: Increased circulating leptin level inhibits folliculogenesis in vespertilionid bat, Scotophilus heathii. Mol Cell Endocrinol 2011, 337(1-2):24-35.

32. Ku SY, Kim SD, Jee BC, Suh CS, Choi YM, Kim JG, Moon SY, Kim SH: Clinical efficacy of body mass index as predictor of in vitro fertilization and embryo transfer outcomes. J Korean Med Sci 2006, 21(2):300-303.

33. Esinler I, Bozdag G, Yarali H: Impact of isolated obesity on ICSI outcome. Reprod Biomed Online 2008, 17(4):583-587.

34. Nichols JE, Crane MM, Higdon HL, Miller PB, Boone WR: Extremes of body mass index reduce in vitro fertilization pregnancy rates. Fertil Steril 2003, 79(3):645-647.

35. Rogers PA: Structure and function of endometrial blood vessels. Hum Reprod Update 1996, 2(1):57-62.

36. Zaidi J, Campbell S, Pittrof R, Tan SL: Endometrial thickness, morphology, vascular penetration and velocimetry in predicting implantation in an in vitro fertilization program. Ultrasound Obstet Gynecol 1995, 6(3):191-198. 
37. Sivitz WI, Wayson SM, Bayless ML, Sinkey CA, Haynes WG: Obesity impairs vascular relaxation in human subjects: hyperglycemia exaggerates adrenergic vasoconstriction arterial dysfunction in obesity and diabetes. J Diabetes Complications 2007, 21(3):149-157.

38. Carrell DT, Jones KP, Peterson CM, Aoki V, Emery BR, Campbell BR: Body mass index is inversely related to intrafollicular HCG concentrations, embryo quality and IVF outcome. Reprod Biomed Online 2001, 3(2):109-111.

39. Winter E, Wang J, Davies MJ, Norman R: Early pregnancy loss following assisted reproductive technology treatment. Hum Reprod 2002, 17(12):3220-3223.

doi:10.1186/1477-7827-11-57

Cite this article as: Zeng et al:: Impact of obesity on endometrial blood flow in women without polycystic ovarian syndrome during

intracytoplasmic sperm injection. Reproductive Biology and Endocrinology 2013 11:57.

\section{Submit your next manuscript to BioMed Central and take full advantage of:}

- Convenient online submission

- Thorough peer review

- No space constraints or color figure charges

- Immediate publication on acceptance

- Inclusion in PubMed, CAS, Scopus and Google Scholar

- Research which is freely available for redistribution 